\title{
FRACTAL APPROACH TO EROSION THRESHOLD OF BENTONITES
}

\author{
Y. F. XU ${ }^{*, \dagger, \ddagger}$ and X. Y. LI* \\ *Department of Civil Engingeering, Shanghai Jiao Tong University \\ Shanghai 200240, P. R. China \\ ${ }^{\dagger}$ Geotechnical Engineering Center, Wentian College \\ Maanshan 243000, P. R. China \\ ¥yongfuxu@sjtu.edu.cn
}

Received October 24, 2017

Accepted November 28, 2017

Published April 2, 2018

\begin{abstract}
Bentonite has been considered as a candidate buffer material for the disposal of high-level radioactive waste (HLW) because of its low permeability, high sorption capacity, self-sealing characteristics and durability in a natural environment. Bentonite erosion caused by groundwater flow may take place at the interface of the compacted bentonite and fractured granite. Surface erosion of bentonite flocs is represented typically as an erosion threshold. Predicting the erosion threshold of bentonite flocs requires taking into account cohesion, which results from interactions between clay particles. Beyond the usual dependence on grain size, a significant correlation between erosion threshold and porosity measurements is confirmed for bentonite flocs. A fractal model for erosion threshold of bentonite flocs is proposed. Cohesion forces, the long-range van der Waals interaction between two clay particles are taken as the resource of the erosion threshold. The model verification is conducted by the comparison with experiments published in the literature. The results show that the proposed model for erosion threshold is in good agreement with the experimental data.
\end{abstract}

Keywords: Bentonite Erosion; Erosion Threshold; Bentonite Floc; Fractal Aggregate.

\footnotetext{
$\ddagger$ Corresponding author.
}

This is an Open Access article published by World Scientific Publishing Company. It is distributed under the terms of the Creative Commons Attribution 4.0 (CC-BY) License. Further distribution of this work is permitted, provided the original work is properly cited. 


\section{Nomenclature}

$$
\begin{aligned}
& A_{H} \text { - the Hamaker constant, } A_{H} \approx 10^{-20} \mathrm{~J} \\
& C_{a}-\text { a constant } \\
& c_{u} \text { - undrained shear strength } \\
& c_{v} \text { - the vertical consolidation coefficient } \\
& D \text { - the fractal dimension } \\
& d_{1}, d_{2} \text { - the particle diameters } \\
& d_{50, a} \text { - the median diameter of the soil } \\
& \text { aggregates } \\
& d_{a} \text { - the aggregate diameter } \\
& d_{i} \text { - the inter-particle distance } \\
& d_{p} \text { - the primary particle diameter } \\
& e_{2} \text { - the void ratio of specimen after } \\
& \text { swelling deformation test } \\
& F_{c p} \text { - cohesive force of primary particles } \\
& f_{a} \text { - a shape constant } \\
& G_{s} \text { - the specific gravity } \\
& K \text { - a constant } \\
& k \text { - a constant } \\
& k_{g} \text { — the shape factor of aggregates } \\
& M_{E} \text { - an erosion parameter } \\
& m_{2} \text { - the specimen mass after } \\
& \text { swelling deformation test } \\
& m_{s} \text { - the solid mass of specimen } \\
& m_{w} \text { — the mass of the pore water } \\
& N \text { - the number of primary particles } \\
& V_{2} \text { — the specimen volume after } \\
& \text { swelling deformation test } \\
& V_{p} \text { — the volumes of the pore volume } \\
& V_{s} \text { — the volumes of the soil particles } \\
& w_{0} \text { - the water content } \\
& \alpha_{a}=A_{H} f_{a} /\left(24 K^{2} C_{a} d_{p}\right) \\
& \beta_{a}=\alpha_{a} k^{1 /(3-D)} \\
& \gamma \text { - an empirical coefficient } \\
& \rho_{a} \text { - the aggregate density } \\
& \rho_{b} \text { — the bulk density, } \\
& \rho_{d} \text { - the dry density of the bed, } \\
& \rho_{d 2} \text { - the dry density of specimen after } \\
& \text { swelling deformation test } \\
& \rho_{e} \text { - effective density } \\
& \rho_{p} \text { — the density of primary particle } \\
& \rho_{w} \text { - the density of water } \\
& \tau_{c} \text { - erosion threshold of surface erosion } \\
& \text { (the critical shear stress) } \\
& \tau_{c 0} \text { - a scaling parameter } \\
& \tau_{m c} \text { - the erosion threshold of mass erosion } \\
& \tau_{f c} \text { - the erosion threshold of fluid mud erosion } \\
& \tau_{y} \text { — the yield strength } \\
& \phi \text { - the aggregate porosity } \\
& \phi_{s} \text { - the solid volume fraction } \\
& \phi_{s, 0} \text { - the volumetric concentration }
\end{aligned}
$$

\section{INTRODUCTION}

Several countries plan to use bentonite clay as the buffer and backfill material in nuclear waste repositories 173 Compacted bentonite clay around the canister protects it from chemical and mechanical disturbances. Should large amounts of bentonite clay be lost by erosion, the canister would be less protected. ${ }^{4}[6$ If the density of a compacted bentonite buffer becomes very low due to a swelling, the highly hydrated bentonite platelets become disassociated, and the macroscopic behavior of the bentonite becomes gel-like, called as a bentonite gel ${ }^{7-9}$ It might corrode faster and the release of nuclides would also increase if the canister is breached 10 Clay erosion occurs when erosive forces exceed the resistive forces within the clay flocs, which include gravity, friction, cohesion and adhesion.13/14 Idealized diagrammatic representation of the erosion characteristics of clay is shown in Fig. 1$]^{15}$ It distinguishes three erosion modes: floc erosion, surface erosion and mass erosion. Floc erosion is the disruption of individual flocs or parts of flocs. This occurs when the flow-induced peak stresses exceed the strength of unconsolidated flocs and/or their mutual cohesive/adhesive bonds 15 Surface erosion takes place as a detachment of clay aggregates, and is a drained failure process (no pore water pressure gradients) which occurs when the mean shear stress is larger than the erosion threshold $\frac{13}{13}$ Mass erosion shows that the clay flocs fail at some plane below the clay surface $\frac{15}{15}$ Most studies on the floc erosion of clay are conducted!16]17 However, the surface erosion is the main path for clay to be lost in the surrounding water ${ }^{10}$ Erosion threshold is the

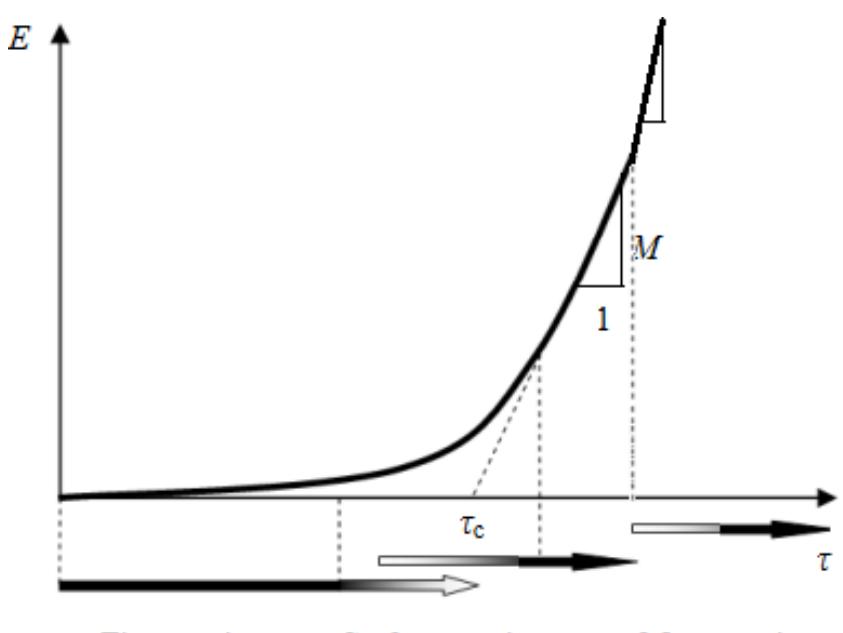

Floc erosion Surface erosion Mass erosion

Fig. 1 Classification of erosion modes for clay (Ref. 15). 
main parameter to express the surface erodibility of clay 13

To model surface the erosion of clay requires knowledge of the erosion threshold for the initiation of the motion of clay flocs $\frac{18}{18}$ An erosion threshold is the critical shear stress $\left(\tau_{c}\right)$ that initiates floc erosion 19 Similar to most empirical models for clay erosion, models for surface erosion have been written as a function of excess shear stress 15 .

$$
E=M\left(\tau-\tau_{c}\right),
$$

where $M$ is an erosion parameter, $\tau_{c}$ is the erosion threshold (the critical shear stress), which is the stress on the clay surface at which the clay floc first starts to erode. Raudkivi and Tan $\underline{20}$ gave a model to determine the number of bonds per unit area and the activation energy to break the interparticle chemical bonds of essentially pure clays. Nearing 21 developed a probabilistic model that incorporated the tensile strength of the soil, which is an aggregate measure of the resistant forces of both chemical and organic bonds. Mitchener and Torfs 22 presented a relationship between the erosion threshold and bulk density for the data from artificial mixed sediment beds. The relationship was of the form

$$
\tau_{c}=0.015 \times\left(\rho_{a}-\rho_{w}\right)^{0.73} .
$$

Currently no reliable method exists to estimate the erosion threshold for clay based on the clay properties. ${ }^{23}$ It is well known that clay particles tend to form complex structures, called flocs, due to cohesive or adhesive forces, and the floc networks tend to be self-similar. ${ }^{2425}$ Based on the scale invariance of a self-similar fractal structure, the number of bonds in an erosion plane does not depend on the size of flocs. Kranenburg ${ }^{\sqrt{25}}$ presented the erosion threshold as follows:

$$
\tau_{c} \propto\left(\rho_{a}-\rho_{w}\right)^{2 /(3-D)},
$$

where $\tau_{c}$ is the erosion threshold, $\rho_{a}$ is the bulk density of clay flocs, $D$ is the fractal dimension. While Yeung and Pelton ${ }^{26}$ found that the erosion threshold was a function of the floc size, Sonntag and Russe ${ }^{27}$ suggested an empirical equation for the erosion threshold, which was the yield force divided by the cross-sectional area of clay flocs, based on a power law:

$$
\tau_{c}=\tau_{c 0}\left(\frac{d_{a}}{d_{p}}\right)^{\gamma \frac{2 D}{3}},
$$

where $\tau_{c 0}$ is a scaling parameter, $d_{a}$ is the floc diameter, $d_{p}$ is the particle diameter, $\gamma$ is an empirical coefficient, ranges between 0.5 and $1.5 \stackrel{28}{28}$ Following the definition of the solid's volume fraction within flocs, it can be concluded that the erosion threshold is not constant but a function of the floc structure and size. Son and $\mathrm{Hsu}^{29}$ assumed that the erosion threshold of flocs depends on the strength of the inter-particle bonds and the number of the interparticle bonds within flocs, and gave an expression of the erosion threshold:

$$
\tau_{c}=\left(\frac{\pi}{6}\right)^{\frac{2}{3}} F_{c p}\left(\frac{d_{a}}{d_{p}}\right)^{\frac{2 D}{3}} d_{a}^{-2},
$$

where $F_{c p}$ is the cohesive force of primary particles, and is considered as an empirical parameter because it depends on the properties of clay flocs.

The difficulties in modeling the erodibility of clay are due to the strong inter-particle attractions found in the cohesive sediment 15 The interparticle attraction is influenced by a large number of clay properties that interact in complex ways. The hierarchical nature of the cohesive mechanisms (electrostatic-clay bonds) results in clay with complex cohesive properties 19 Fractal model for the clay flocs offers a good method to study the erosion threshold of clay. ${ }^{25 \mid 29}$ In this paper, according to the fractal model for the clay flocs, a new formula for the erosion threshold of clay flocs is proposed and verified by the published data. The proposed model for the erosion threshold was compared with the Kranenburg model ${ }^{25}$ and the Son and Hsu model $[29$

\section{FRACTAL FLOCS}

Clay minerals are the most electrochemically active, and tend to form clay flocs due to the cohesive or adhesive forces among clay particles. The clay flocs have a fractal structure, i.e. a fractal surface, a fractal volume and a fractal mass. ${ }^{25}$ The number of similar primary particles in an aggregate may be given by

$$
N=k_{g}\left(\frac{d_{a}}{d_{P}}\right)^{D},
$$

where $N$ is the number of primary particles, $k_{g}$ is the shape factor of aggregates, $d_{a}$ is the floc diameter, $d_{p}$ is the primary particle diameter and $D$ is the fractal dimension.

The number of primary particles within clay flocs, $N$, is derived from the definition of $N=$ $\phi_{s}\left(d_{a} / d_{p}\right)^{3}$, here $\phi_{s}$ is the solid volume fraction. The 
solid volume fraction is given by

$$
\phi_{s}=k\left(\frac{d_{a}}{d_{p}}\right)^{D-3},
$$

where $\phi_{s}$ is the solid volume fraction, $k$ is a constant. The porosity of the clay flocs, given by the definition $\phi=1-\phi_{s}$, can be written as

$$
\phi=1-k\left(\frac{d_{a}}{d_{p}}\right)^{D-3},
$$

where $\phi$ is the floc porosity.

The floc density is defined as the weighted average density of particles and water, and can be calculated as

$$
\rho_{a}=\rho_{p} \phi_{s}+\left(1-\phi_{s}\right) \rho_{w} .
$$

Rearranging Eq. (8), the effective density $\left(\rho_{e}=\rho_{a}-\right.$ $\rho_{w}$ ) of flocs is expressed as

$$
\frac{\rho_{a}-\rho_{w}}{\rho_{p}-\rho_{w}}=\phi_{s}=k\left(\frac{d_{a}}{d_{p}}\right)^{D-3},
$$

where $\rho_{a}$ is the floc density, $\rho_{p}$ is the density of primary particle, $\rho_{w}$ is the water density.

The fractal dimension of Kunigel V1 bentonite flocs was determined from the solid volume fraction or the effective density. The physical properties of Kunigel V1 bentonite are listed in Table 1. The bentonite flocs are produced by swelling deformation tests. The swelling deformation of Kunigel V1 bentonite was conducted on a modified oedometer. The specimen was produced by compaction and was set up on the test apparatus. Silicone grease was applied to the inner cell wall to reduce the friction between the specimen and cell wall. After applying the prescribed vertical pressure to the specimen, the distilled water was supplied to the specimen. The change in the specimen height and weight was measured after testing. The initial height of compacted specimen is $10 \mathrm{~mm}$. The solid volume fraction of

Table 1 Physical Properties of Bentonite.

\begin{tabular}{lc}
\hline Physical Parameter & Value of Parameter \\
\hline Specific gravity, $G_{s}$ & 2.79 \\
Liquid limit, $w_{L}(\%)$ & 473.9 \\
Plastic limit, $w_{p}(\%)$ & 26.6 \\
Plastic index, $I_{p}$ & 447.3 \\
Montmorilloite content $(\%)$ & 48 \\
Specific surface area $\left(\mathrm{m}^{2} / \mathrm{g}\right)$ & 810 \\
Cation exchange capacity $(\mathrm{mEq} / \mathrm{g})$ & 0.732 \\
\hline
\end{tabular}

Kunigel V1 bentonite after swelling deformation tests is calculated by

$$
\phi_{s}=1-\frac{e_{2}}{1+e_{2}},
$$

where $e_{2}$ is the void ratio of specimen after swelling deformation tests, and is expressed by

$$
e_{2}=\frac{G_{s}}{\rho_{d 2}}-1,
$$

where $G_{s}$ is the specific gravity of bentonite, $\rho_{d 2}$ is the dry density of specimen after swelling deformation tests, $\rho_{d 2}=m_{s} / V_{2}, m_{s}$ and $V_{2}$ are the solid mass and the volume of specimen after swelling deformation tests. Experimental data of the relationship between the solid volume fraction and the floc size of Kunigel V1 bentonite are shown in Fig. 2, where the floc size is replaced by the specimen height. The fractal dimension of the bentonite flocs is 2.15, obtained from Fig. 2. The relationship between the effective density and the specimen height of Kunigel V1 bentonite is shown in Fig. 3 .

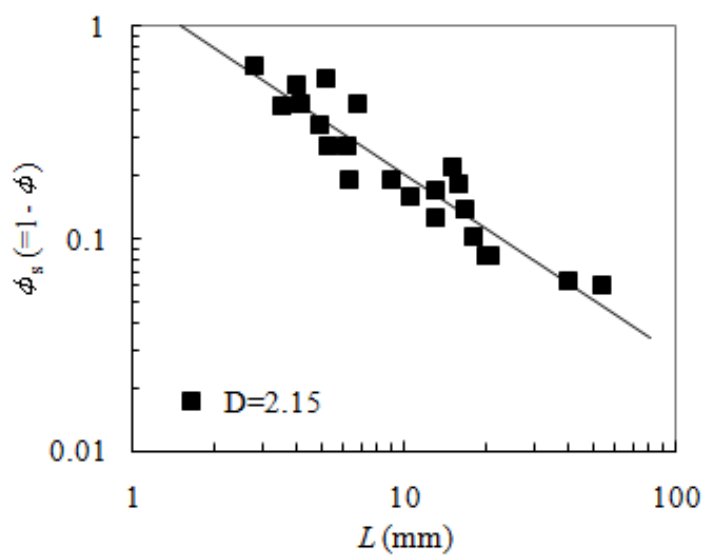

Fig. 2 Relationship between solid volume fraction and sample size of Kunigel V1 bentonite.

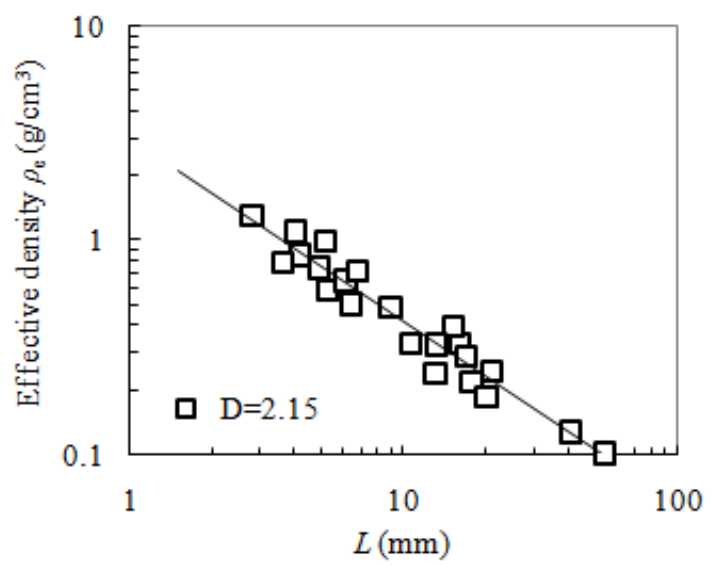

Fig. 3 Relationship between effective density and sample size of Kunigel V1 bentonite. 
The effective density of specimen after swelling deformation tests is calculated by $\rho_{e}=\rho_{a}-\rho_{w}$, $\rho_{a}=m_{2} / V_{2}, m_{2}$ and $V_{2}$ are the mass and volume of the specimen after swelling deformation tests. The fractal dimension of the bentonite flocs is 2.15, obtained from Fig. 3 The fractal dimension of bentonite flocs obtained from the solid volume fraction is consistent with that from the effective density. The solid volume fraction and the effective density are calculated independently from the physical properties of specimen after swelling deformation tests. The verification of Eqs. (7) and (9) is conducted by the results shown in Figs. 2 and 3 .

Kaoline suspensions of $7.5 \mathrm{~kg} / \mathrm{m}^{3}$ are flocculated by the consecutive dosage of inorganic salt and nonionic polymer. ${ }^{30}$ The size distribution of kaoline flocs was measured by a centrifugal sedimentation particle analyzer. The mean diameter of the longest and shortest diameters is employed as the diameters of the kaoline flocs. Assuming the kaoline flocs are a spherical particle of the mean diameter, the effective density, which is the difference between the densities of the kaoline floc and the water medium, was calculated by the equation of terminal velocity for a spherical particle. The relationship of the effective density versus the floc size is shown in Fig. 4. According to Eq. (9), the fractal dimensions are 2.4 and 1.8 on the concentration of dosed polymer being $3 \mathrm{~g} / \mathrm{cm}^{3}$ and $7.5 \mathrm{~g} / \mathrm{cm}, \frac{3}{,}$ respectively.

\section{EROSION THRESHOLD OF CLAY FLOCS}

The relationships between the erosion rate and shear stress of kaoline and Na-montmorillonite are shown in Fig. 5. Experimental data of kaolin and

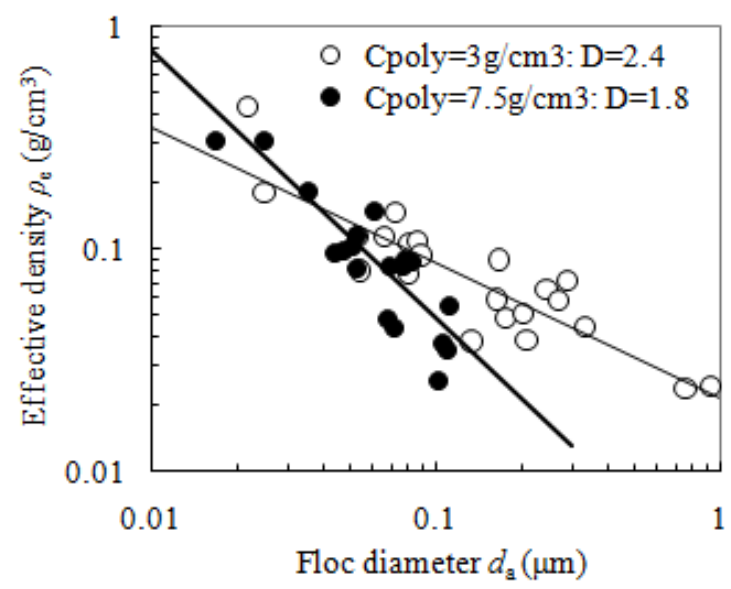

Fig. 4 Relationship between effective density and floc diameter (data from Ref. 31).

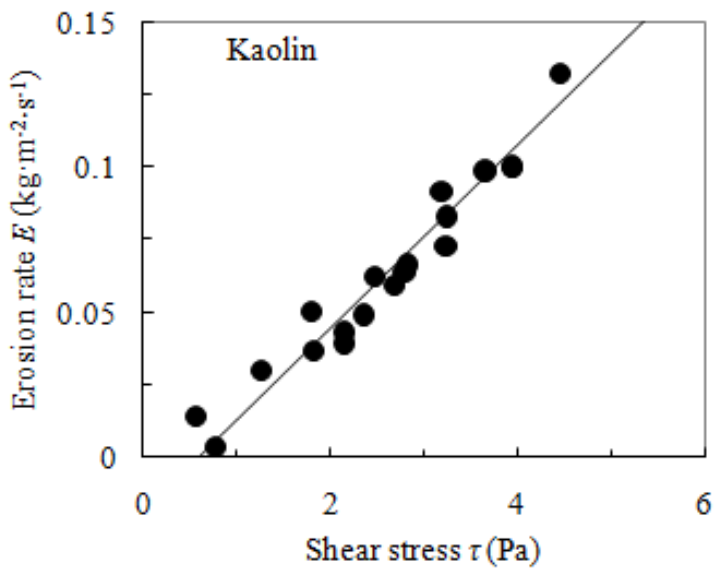

(a)

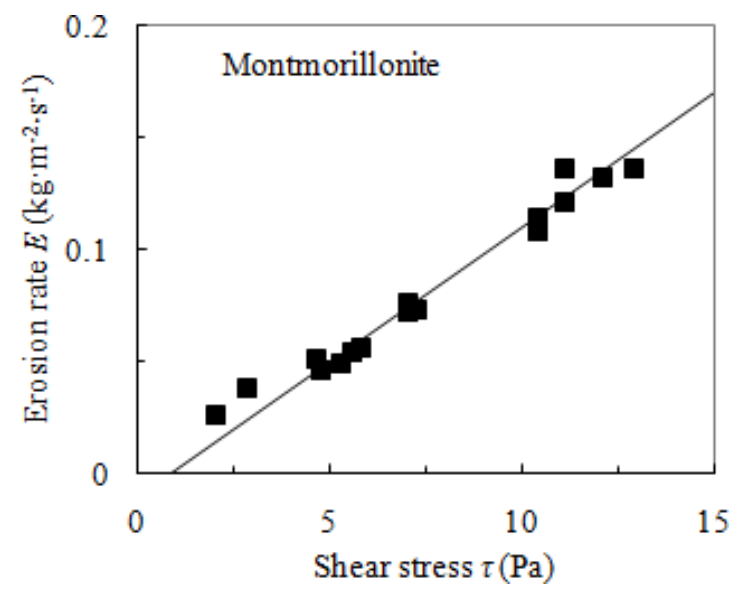

(b)

Fig. 5 Surface erosion thresholds of clays.

Na-montmorillonite are collected from Higashitani et $a l .31$ and Shaikh et al., ${ }^{32}$ respectively. According to Eq. (1), the surface erosion thresholds of kaolin and Na-montmorillonite are $0.75 \mathrm{~Pa}$ and $0.9 \mathrm{~Pa}$, respectively, obtained from Fig. 5. The values of the erosion threshold are too little to be accurately measured by erosion experiments. Meanwhile, the erosion laboratory tests are difficult and time consuming to perform. Thus, it is very important and valuable to present a method with the physical meaning to determine the surface erosion threshold of clays.

Erosion of clays consists of three separate processes. First is the separation, detachment, or initiation of motion of clay flocs from among the neighboring aggregates, second is the transport of these detached flocs; and third is an increase in the particle transport rate along a surface flow path that results in the removal of flocs from the clay surface. The stability of clay flocs in an aquatic environment 
is dependent on the balance between hydrodynamic forces that cause erosion and inter-particle attraction within clays that resist it. Erosion occurs when the hydrodynamic forces that cause erosion exceed the resistive forces (inter-particle attraction) within clays. The resistive forces, inter-particle attraction refers to the attraction of clay colloids by electrochemical forces. Israelachvili ${ }^{33}$ gave an expression for the inter-particle attraction of van der Waals between two particles:

$$
F_{H}=\frac{A_{H} d_{1} d_{2}}{12\left(d_{1}+d_{2}\right) d_{i}^{2}},
$$

where $A_{H}$ is the Hamaker constant, $A_{H} \approx 10^{-20} \mathrm{~J}$, $d_{1}$ and $d_{2}$ are the particle diameters, $d_{i}$ is the interparticle distance. The distance $d_{\mathrm{i}}$ between the centers of two particles is obtained by subtracting one diameter 34 .

$$
d_{i}=K d_{p},
$$

where $K$ is a constant. The clay flocs are loosely in contact with each other, especially in the process of the surface erosion. Thus, the inter-particle distance has the considerable value of the particle diameters. It is observed that clay flocs are often disaggregated into two roughly equal-sized flocs in erosion. ${ }^{35}$ Hence, it is assumed here that during the surface erosion, clay flocs are divided by the plane which contains the center of flocs as the two daughter flocs have the same size after erosion. It is assumed that $d_{1}=d_{2}=d_{p}$, Eq. (12) changes to

$$
F_{H}=\frac{A_{H}}{24 K^{2}} \frac{1}{d_{p}} .
$$

According to Eq. (14), the erosion threshold can be written as

$$
\tau_{c}=\frac{F_{H}}{\pi d_{a}^{2} / 4}=\frac{A_{H}}{6 \pi K^{2} d_{p}} \frac{1}{d_{a}^{2}} .
$$

Equation (15) is the same equation as the erosion threshold equation (Eq. (3)) proposed by Kranenburg. 25

The number of primary particles in the erosion plane should be a function of the floc size and its fractal dimension. Consequently, an equation for the number of primary particles $N$ in the plane crossing the floc center can be derived as 29

$$
N=f_{a}\left(\frac{d_{a}}{d_{p}}\right)^{\frac{2 D}{3}},
$$

where $f_{a}$ is a shape constant. The magnitude of resistive forces is the product of the number of primary particles within the flocs and the magnitude of the cohesive force between the primary particles, i.e. $F_{a}=N F_{H}$. The resistive force against erosion of flocs is presented as follows:

$$
F_{a}=\frac{A_{H} f_{a}}{24 K^{2}} \frac{1}{d_{p}}\left(\frac{d_{a}}{d_{p}}\right)^{\frac{2 D}{3}} .
$$

For fractal flocs, the area of the erosion plane equals $A_{a}=\pi N d_{p}^{2} / 4$, is given by

$$
A_{a}=C_{a}\left(\frac{d_{a}}{d_{p}}\right)^{D}
$$

where $C_{a}$ is a constant and $C_{a}=\pi k_{g} d_{p}^{2} / 4$. The erosion threshold of clay flocs can be given by dividing the resistive forces by the area of erosion plane, and is written as follows:

$$
\tau_{c}=\alpha_{a}\left(\frac{d_{a}}{d_{p}}\right)^{-\frac{D}{3}},
$$

where $\alpha_{a}=A_{H} f_{a} /\left(24 K^{2} C_{a} d_{p}\right)$. The surface erosion threshold can be expressed by the solid volume fraction $\left(\phi_{s}\right)$ and the effective density $\left(\rho_{e}\right)$, and is written as follows:

$$
\begin{aligned}
& \tau_{c}=\beta_{a} \phi_{s}^{\frac{D}{3(D-3)}} \\
& \tau_{c}=\beta_{a}\left(\frac{\rho_{a}-\rho_{w}}{\rho_{p}-\rho_{w}}\right)^{\frac{D}{3(3-D)}},
\end{aligned}
$$

where $\beta_{a}=\alpha_{a} k^{1 /(3-D)}$.

\section{VERIFICATION OF THE EROSION THRESHOLD}

The verification of the proposed model was conducted by comparing with the experimental data of the surface erosion threshold. The verification consists of two parts: one is the determination of the floc fractal dimension from the relationship between the effective density and floc size, and two is the model verification by comparing the prediction using the fractal dimension of the proposed model with the experimental data of the erosion threshold.

Zhong et al ${ }^{36}$ investigated the fractal structure of kaolin flocs using in situ particle image velocimetry (PIV) and microbalance without humic acid. The derivation of the floc fractal dimension from the power function of dry mass and characteristic length is shown in Fig. 6f for kaolin flocs after 30 min of slow stiring when the flocs had reached their maximum steady-state size. The mass of floc aggregates 


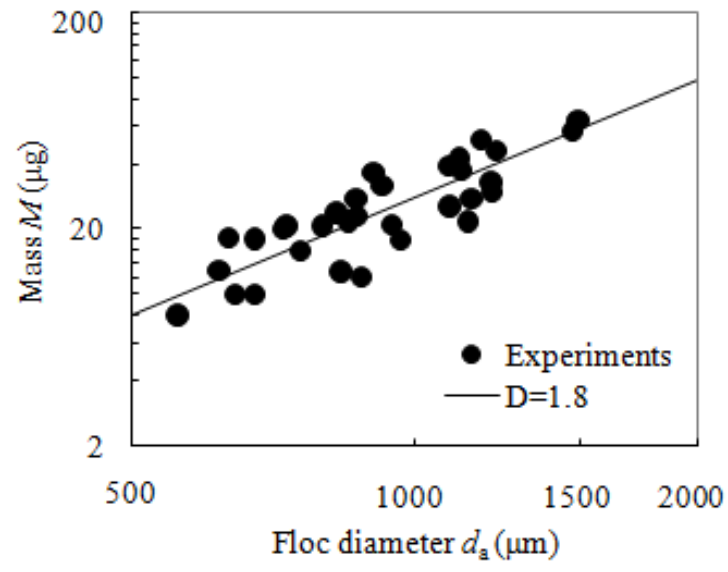

Fig. 6 Relationships between floc mass and floc diameter of kaolin (data from Ref. 36).

scales with their size according to Eq. (21):

$$
M \propto N=k_{g}\left(\frac{d_{a}}{d_{P}}\right)^{D},
$$

where $M$ is the dry mass of flocs. The fractal dimension of kaolin flocs is nearly 1.8 for the coagulants under investigation based on the slope of the logarithmic relationship between the dry mass and size. The fractal dimension of kaoline flocs formed at the same condition can be used to prediction the erosion threshold. Ravisangar et al. .37 measured the velocity and erosion threshold using a one-dimensional laserDoppler velocimetry (LDV) system, and found that kaoline edges became less positive as the $\mathrm{pH}$ was increased, and $F-F$ became the dominant mode of particle association for high $\mathrm{pH}(\mathrm{pH}>7)$ and low ionic strength $(0.004 \mathrm{M})$ conditions to form a dispersed suspension. The result in Fig. 7 shows that erosion threshold increases slightly with the

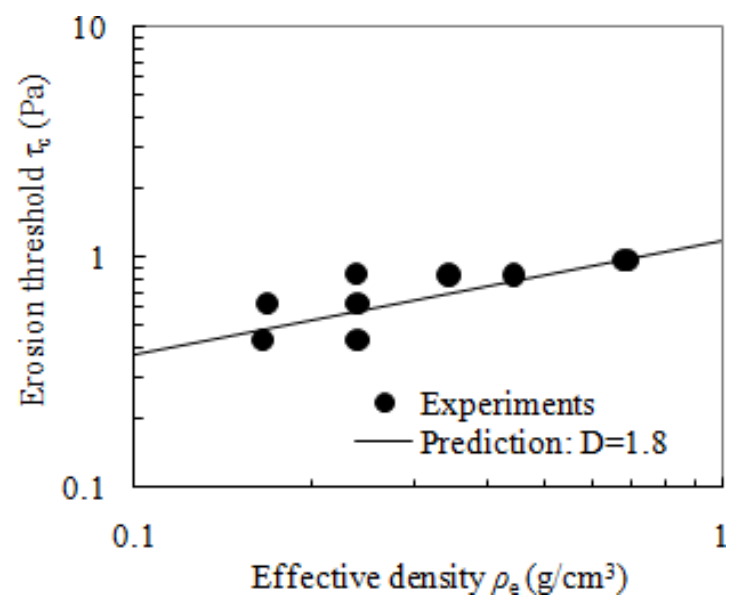

Fig. 7 Relationships between erosion threshold and effective density of kaolin (data from Ref. [37). effective density with a power function. Predictions of the erosion thresholds are compared with the experiments. It is found that the predictions of the proposed model well match with the experiments of the erosion thresholds.

Experimental data of Graneros clayey soil, Osorno clayey soil and Pemehue clayey soil was given by Seguel and Horn $\stackrel{[38}{r}$ These three clayey soils were sampled from different places of the central valley of Chile. Graneros clayey soil was a mollisol. Osorno clayey soil was a characteristic volcanic ash soil from south Chile. Both Osorno clayey soil and Pemehue clayey soil are dominated by allophane. Samples of these three soils were collected at the depth of $0-15 \mathrm{~cm}$.

Soil aggregates were separated softly at field water content followed by complete water saturation. Soil aggregates were equilibrated in a pressure plate extractor at different suctions $(\mathrm{pF}=1.78$, 2.70 and 4.48). Bulk density was measured by the cylinders taken at field water content. The indirect tensile strength was measured using crushing tests. The aggregate sample size ranged from $0.5 \mathrm{~cm}$ to $4 \mathrm{~cm}$. Twenty-five aggregate samples were conducted under per suction.

Seguel and Horn ${ }^{38}$ gave the experimental data of the bulk density of clayey soils. The bulk density is defined as

$$
\rho_{b}=\frac{m_{s}}{V_{s}+V_{p}},
$$

where $\rho_{b}$ is the bulk density, $m_{s}$ is the mass of the soil particles, $V_{s}$ and $V_{p}$ are the volumes of the soil particles and the pore volume in the soil samples. The relationship between the bulk density and the floc density is given by

$$
\rho_{a}=\frac{m_{s}+m_{w}}{V_{s}+V_{p}}=\rho_{b}+\phi \rho_{w},
$$

where $\rho_{a}$ is the floc density, $m_{w}$ is the mass of the pore water, $\phi$ is the soil porosity. The soil porosities are $0.691,0.744$ and 0.767 for Graneros clayey soil, Osorno clayey soil and Pemehue clayey soil, respectively.

The effective density $\left(\rho_{e}\right)$ can be calculated from Eq. (23) using the bulk density of clayey soils. The relationship between the effective density and the aggregate size is shown in Fig. 8. It can be seen from Fig. 8 that the relationship between the effective density and the aggregate size manifests a linear regression in the $\log -\log$ plane. According to Eq. (9), the fractal dimension can be determined from the linear regressions. The floc fractal 


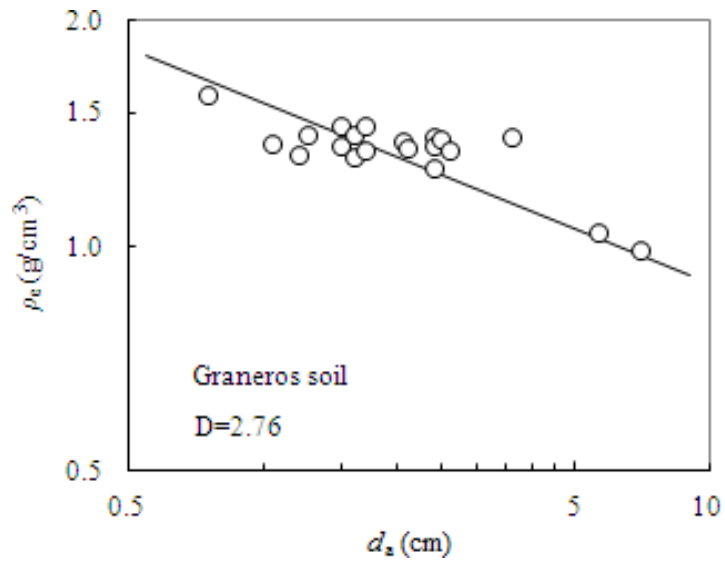

(a)

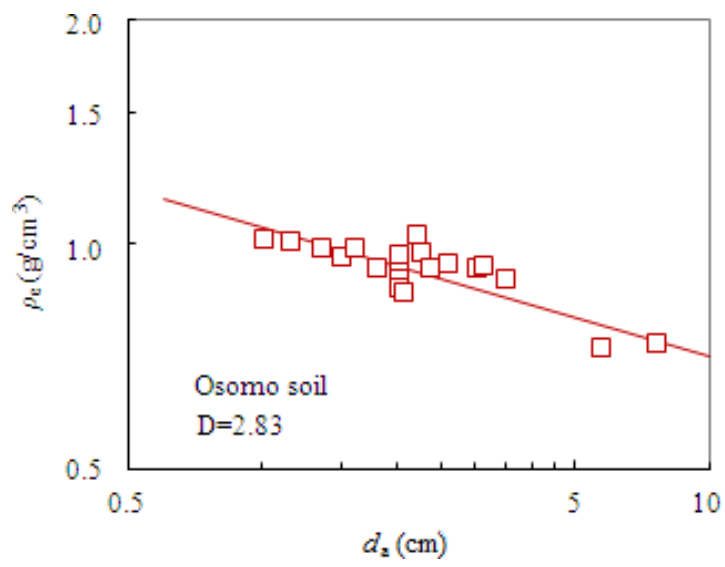

(b)

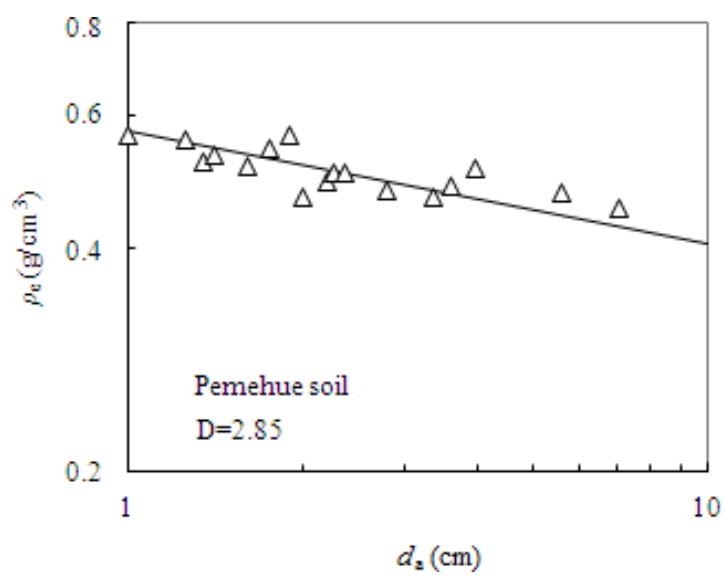

(c)

Fig. 8 The fractal dimension obtained from the relationship between the effective density and aggregate diameter (data from Ref. 38).

dimensions of Graneros clayey soil, Osorno clayey soil and Pemehue clayey soil are 2.76, 2.83 and 2.85, respectively. Predictions of the proposed model (Eq. (19)) are compared with the experimental data of the erosion threshold for the Graneros clayey soil,

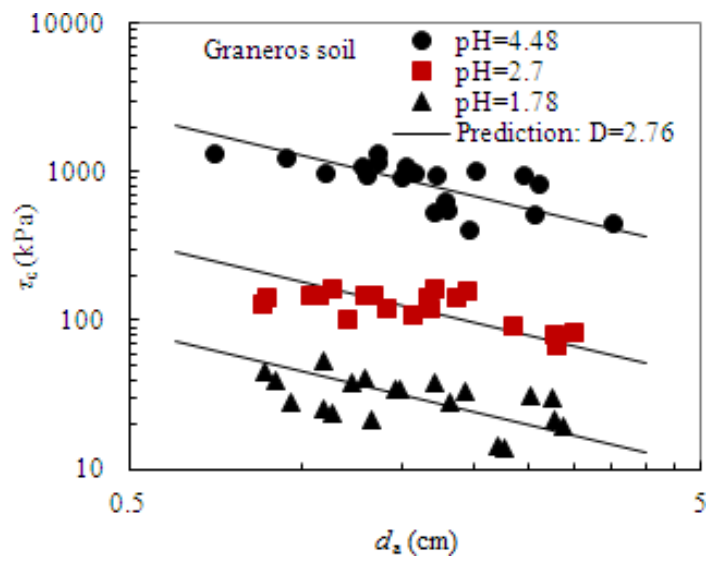

(a)

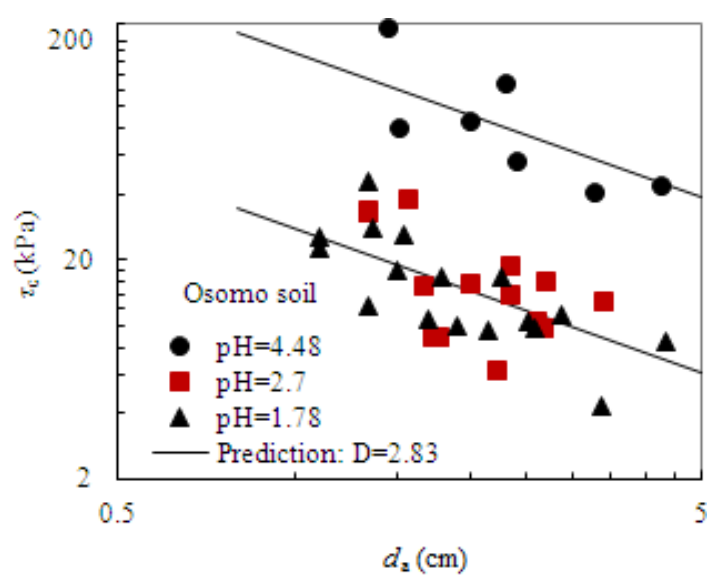

(b)

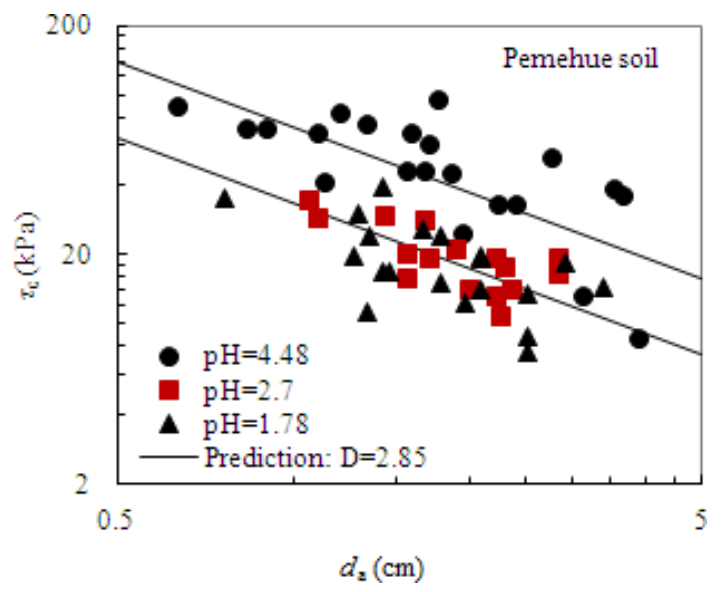

(c)

Fig. 9 Comparison between the proposed model and the experimental data (data from Ref. 38).

Osorno clayey soil and Pemehue clayey soil in Fig. 9. In Fig. 9, $\mathrm{pF}$ is the matric suction. The more is the matric suction, the larger is the erosion threshold. Based on Eq. (20), the slopes in Fig. 9] are calculated using the floc fractal dimension obtained 
from Fig. 8. The erosion threshold of clayey soils has different values for the samples with different maric suctions. The predictions of the erosion threshold well match with the experimental data for three different matric suctions in Fig. 9, It means that the proposed model had a high accuracy to predict the erosion threshold.

\section{COMPARISON WITH THE KRANENBURG MODEL}

The proposed model for the erosion threshold on base of the fractal flocs is different from the Kranenburg 25 model. The Kranenburg model can be written as another form

$$
\tau_{c} \propto d_{a}^{-2} .
$$

Experimental data on the erosion threshold of cohesive soils are shown in Fig. 10 ${ }^{40}$ The cohesive aggregate cores were taken from the western European continental margin under a water depth of 212 $4940 \mathrm{~m}$. The median diameter of cohesive aggregates ranges from $0.125-2.403 \mathrm{~mm}$. The slope of the regress line is 0.43 , and corresponding to the fractal dimension of 1.29 in Fig. 10. The fractal dimension of cohesive flocs obtained from Fig. 10 is located in the range of $0-3.0$, which is the value range for the floc fractal dimension. This means that the proposed model can be used to predict the erosion threshold of the cohesive flocs.

The slopes of the regress lines in the log-log plane are far less than 2 in Fig. 10. The regression results show that the experimental data deviated from the Kranenburg model. Thus, the Kranenburg model cannot be used to predict the relationship between the erosion threshold and the aggregate diameter.

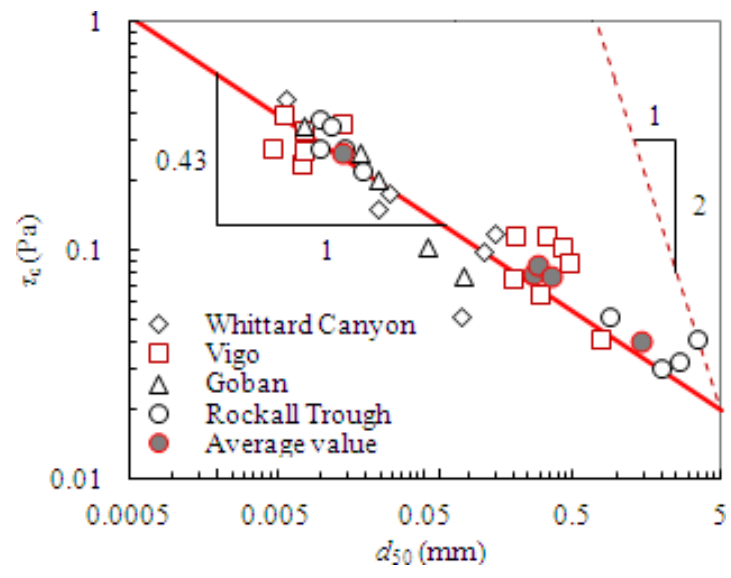

Fig. 10 Comparison between the proposed model and the Kranenburg model with experimental data (Ref. 39).

\section{COMPARISON WITH THE SON AND HSU MODEL}

According to Eqs. (51) and (91), the Son and $\mathrm{Hsu}$ model can be written as follows:

$$
\tau_{c} \propto_{a} \phi_{s}^{\frac{2}{3}}=\left(\frac{\rho_{a}-\rho_{w}}{\rho_{p}-\rho_{w}}\right)^{\frac{2}{3}} .
$$

Equation (25) is different from the proposed model (Eq. (20)) for the erosion threshold on the base of the fractal aggregates.

Figure 11 shows the experimental data of the erosion threshold of kaoline flocs. The relationship between the erosion threshold and the solid volume fraction of kaolinite flocs is shown in Fig. 11] given by Nasser and James 40 The slopes of the regress lines in Fig. 11a are 5.78, 6.58, 6.81, 7.08, 6.07 and 6.66, respectively for A100, A130, A130 LMW, C492, C496 and C446. The fractal dimensions of

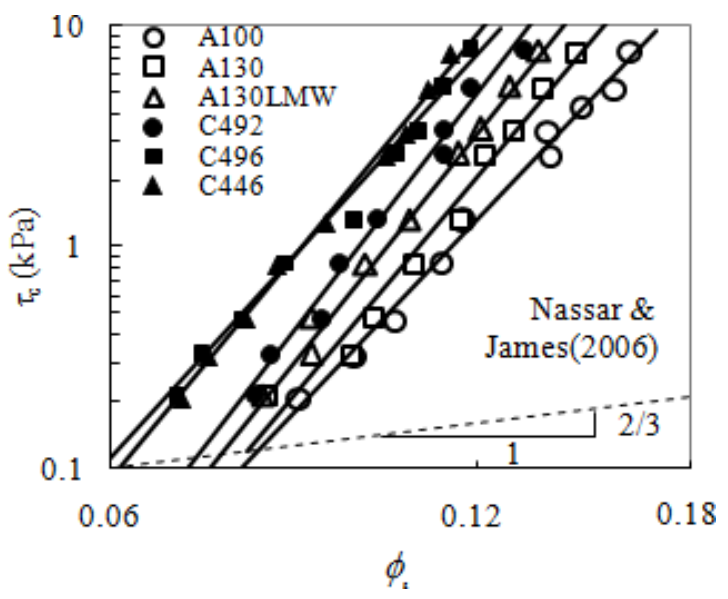

(a) Data from Ref. 40

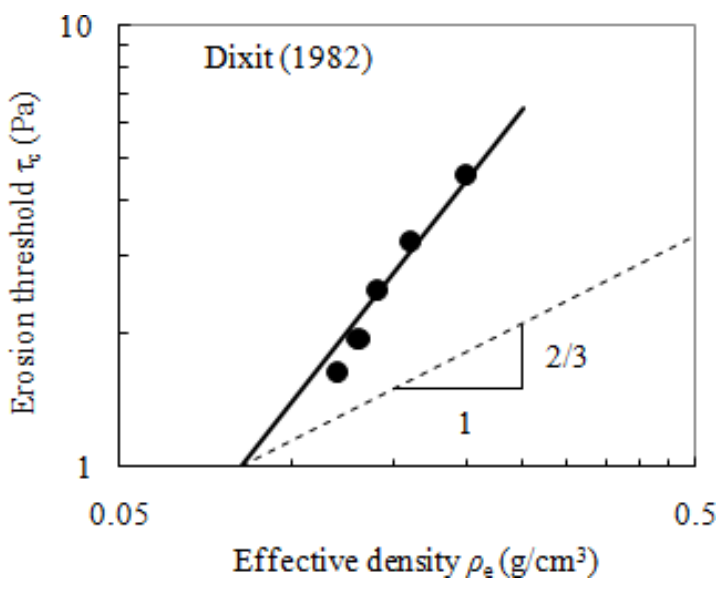

(b) Data from Ref. 41

Fig. 11 Comparison between the proposed model and the Son and Hsu model with the experimental data of erosion threshold. 
A100, A130, A130 LMW, C492, C496 and C446 are $2.84,2.86,2.86,2.87,2.84$ and 2.86 , respectively.

Dixit 11 gave the relationship between the erosion threshold and effective density (Fig. 111). The slopes of the regress lines in Fig. 11b are 1.66, and the corresponding fractal dimension is 2.50 for kaoline flocs. Sharif and Atkinson ${ }^{42}$ pointed out that the fractal dimension of flocs varied from 2.1 to 2.75.

Predictions of the proposed model are compared with that of the Son and Hsu model in Fig. 11. The slopes of the regress lines in the log-log plane are not $2 / 3$ in Fig. 11. The regression results show that the experimental data deviated from the Son and Hsu model. Thus, the Son and Hsu model cannot be used to predict the relationship between the erosion threshold and the floc effective density.

\section{CONCLUSIONS}

In this paper, we proposed a fractal framework for the surface erosion threshold characteristics of clays, and took effort to relate the surface erosion threshold to the floc size, the effective density and the solid volume fraction of the clay flocs, respectively. The erosion threshold is related the floc size as $\tau_{c}=\alpha_{a}\left(d_{a} / d_{p}\right)^{-D / 3}$, and the erosion threshold is expressed by the solid volume fraction $\left(\phi_{s}\right)$ and the effective density $\left(\rho_{e}\right)$ as $\tau_{c}=\beta_{a}\left(\phi_{s}\right)^{-D / 3(D-3)}$ and $\tau_{c}=\beta_{a}\left[\rho_{e} /\left(\rho_{p}-\rho_{w}\right)\right]^{-D / 3(D-3)}$, respectively. The proposed method can be used to predict the erosion threshold of clay flocs with accuracy.

We also compared the proposed method with the Kranenburg model and the Son and Hsu model, and found that both the Kranenburg model and the Son and Hsu model deviated from the experimental data of the erosion threshold of clay flocs. The Kranenburg model cannot predict the relationship between the surface erosion threshold and the floc size. The Son and Hsu model cannot predict the relationship between the surface erosion threshold and the effective density or the solid volume fraction of clay flocs.

\section{ACKNOWLEDGMENT}

The Key Project of National Nature Science Foundation of China (Grant No. 41630633) is acknowledged for its financial support.

\section{REFERENCES}

1. Y. F. Xu, H. Matsuoka and D. A. Sun, Swelling characteristics of fractal-textured bentonite and its mixtures, Appl. Clay Sci. 22 (2003) 197-209.
2. D. A. Sun, H. Cui and W. J. Sun, Swelling of compacted sand-bentonite mixtures, Appl. Clay Sci. 43 (2009) 485-492.

3. W. M. Ye, F. Zhang, B. Chen, Y. G. Chen, Q. Wang and Y. J. Cui, Effects of salt solutions on the hydro-mechanical behavior of compacted GMZ01 bentonite, Environ. Earth Sci. 72 (2014) 2621-2630.

4. Y. F. Xu, Z. R. Gao, F. F. Chu and C. X. Liu, Fractal model for erosion mass of bentonite colloids, Environ. Earth Sci. 75 (2016) 1330, doi:10.1007/s12665016-6101-8.

5. J. C. Cai, F. S. J. Martínez and M. A. Martín, An introduction to flow and transport in fractal models of porous media: Part I, Fractals 22(3) (2014) 1402001.

6. J. Cai, W. Wei, X. Hu, R. C. Liu and J. J. Wang, Fractal characterization of dynamic fracture network extension in porous media, Fractals 25(2) (2017) 1750023.

7. J. Cai, X. Hu and B. Xiao, Recent developments on fractal-based approaches to nanofluids and nanoparticles aggregation, J. Heat Mass Transf. 105 (2017) 623-637.

8. D. A. Sun et al., Swelling characteristics of GMZ bentonite and its mixtures with sand, Appl. Clay Sci. 83 (2013) 224-230.

9. D. A. Sun et al., Evaluation and prediction of the swelling pressures of GMZ bentonites saturated with saline solution, Appl. Clay Sci. 105 (2015) 207-216.

10. K. Suzuki, H. Asanoand and R. Yagag, Experimental investigations of piping phenomena in bentonitebased buffer materials for an HLW repository, Clay Miner. 48 (2013) 363-382.

11. Y. F. Xu, Surface fractal dimension of swelling clay minerals, Fractals 11(4) (2003) 353-362.

12. Y. Xi, J. J. Chen and Y. F. Xu, Yield strength of fractal aggregates, 22(3) (2014) 1440006.

13. L. P. Sanford, Modeling a dynamically varying mixed sediment bed with erosion, deposition, bioturbation, consolidation, and armoring, Comput. Geosci. 10 (2008) 1263-1283.

14. Y. F. Xu and D. A. Sun, Determination of expansive soil strength using a fractal model, Fractals $\mathbf{9}(1)$ (2001) 51-60.

15. J. C. Winterwerp and W. G. van Kesteren, Introduction to the Physics of Cohesive Sediments in the Marine Environment, Development in Sedimentology, Vol. 56 (Elsevier Press, New York, 2004).

16. L. Moreno, I. Neretnieks and L. C. Liu, Modelling of erosion of bentonite gel by gel/sol flow, Swedish Nuclear Fuel and Waste Management Co., Royal Institute of Technology, TR-10-64 (2010). 
17. C. Degueldre and A. Benedicto, Colloid generation during water flow transients, Appl. Geochem. 27 (2012) 1220-1225.

18. Y. F. Xu, H. Jiang, F. F. Chu and C. X. Liu, Fractal model for surface erosion of cohesive sediments, Fractals 22 (2014) 1440006, doi:10.1142/ S0218348X14400064.

19. R. C. Grabowski, I. G. Droppo and G. Wharton, Erodibility of cohesive sediment: The importance of sediment properties, Earth-Sci. Rev. 105 (2011) 101-120.

20. A. J. Raudkivi and S. K. Tan, Erosion of cohesive soils, J. Hydraul. Res. 22 (1984) 217-233.

21. M. A. Nearing, A probabilistic model of soil detachment by shallow turbulent flow, Trans. Am. Soc. Agric. Eng. 34 (1991) 81-85.

22. H. Mitchener and H. Torfs, Erosion of mud/sand mixtures, Coast. Eng. 29 (1996) 1-25.

23. D. Cossette, K. A. Mazurek and D. Rennie, Critical shear stress from varied method of analysis of a submerged circular turbulent impinging jet test for determining erosion resistance of cohesive soils, in Sixth Int. Conf. ICSE6, Paris, 2012, pp. 11-18 .

24. P. Meakin, Fractal aggregates, Adv. Colloid Interf. Sci. 28 (1998) 249-331.

25. C. Kranenburg, The fractal structure of cohesive sediment aggregates, Estuar. Coast. Shelf Sci. 39 (1994) 451-460.

26. A. K. C. Yeung and R. Pelton, Micromechanics: A new approach to studying the strength and breakup of flocs, J. Colloid Interf. Sci. 184 (1996) 579-585.

27. R. C. Sonntag and W. B. Russel, Structure and breakup of flocs subjected to fluid stresses. II. Theory, J. Colloid Interf. Sci. 115 (1987) 378-389.

28. D. H. Bache, Floc rupture and turbulence: A framework for analysis, Chem. Eng. Sci. 59 (2004) 25212534.

29. M. Son and T. J. Hsu, The effect of variable yield strength and variable fractal dimension on flocculation of cohesive sediment, Water Res. 43 (2009) 3582-3592.

30. K. Higashitani, T. Shibata, H. Kage and Y. Matsun, Formation of pellet flocs from kaoline suspension and their properties, J. Chem. Eng. Jpn. 20 (1987) 152-157.
31. K. Higashitani et al., Formation of pellet flocs from kaoline suspension and their properties, J. Chem. Eng. Jpn. 20(2) (1987) 152-157.

32. A. Shaikh, J. F. Ruff and S. R. Abt, Erosion rate of compacted Na-montmorillonite soils, J. Geotech. Eng. 114 (1998) 296-310.

33. J. Israelachvili, Intermolecular and Surface Forces (Elsevier, New York, 1991).

34. F. Ternat, P. Boyer and F. Anselmet, Erosion threshold of saturated natural cohesive sediments: Modeling and experiments, Water Resour. Res. 44 (2008) W11434.

35. C. H. Tsai and S. C. Hwang, Flocculation of sediment from the Tanshui river estuary, Mar. Freshwater Res. 46 (1995) 383-392.

36. R. S. Zhong, X. H. Zhang, F. Xiao and X. Y. Li, Effects of humic acid on recoverability and fractal structure of alum-kaolin flocs, J. Environ. Sci. 23(5) (2011) 731-737.

37. V. Ravisangar, T. W. Sturm and A. Amirtharajah, Influence of sediment structure on erosional strength and density of kaolinite sediment beds, J. Hydraul. Eng. 131 (2005) 356-365.

38. O. Seguel and R. Horn, Structure properties and pore dynamics in aggregate beds due to wettingdrying cycles, J. Plant Nutr. Soil Sci. 169 (2006) 221-232.

39. L. Thomsen and G. Gust, Sediment erosion thresholds and characteristics of resuspended aggregates on the western European continental margin, DeepSea Res. I Oceanogr. Res. Pap. 47 (2005) 18811897.

40. M. S. Nasser and A. E. James, The effect of polyacrylamide charge density and molecular weight on the flocculation and sedimentation behaviour of kaolinite suspensions, Sep. Purif. Technol. 52 (2006) 241-252.

41. J. G. Dixit, Resuspension potential of deposited kaolinite beds. M.S. thesis, University of Florida, (1982).

42. A. R. Sharif and J. F. Atkinson, Model for surface erosion of cohesive soils, J. Hydraul Eng. 138 (2012) $581-590$. 